\title{
High temperature PEM fuel cell steady-state transport modeling
}

\author{
Viorel IONESCU* \\ Department of Physics and Electronics, Ovidius University of Constanta, 124 Mamaia Blvd, 900527, Romania
}

\begin{abstract}
A fuel cell is a device that can directly transfer chemical energy to electric and thermal energy. Proton exchange membrane fuel cells (PEMFC) are highly efficient power generators, achieving up to 50-60\% conversion efficiency, even at sizes of a few kilowatts. There are several compelling technological and commercial reasons for operating $\mathrm{H}_{2} /$ air PEM fuel cells at temperatures above $100{ }^{\circ} \mathrm{C}$; rates of electrochemical kinetics are enhanced, water management and cooling is simplified, useful waste heat can be recovered, and lower quality reformed hydrogen may be used as the fuel. All of the High Temperature PEMFC model equations are solved with finite element method using commercial software package COMSOL Multiphysics. The results from PEM fuel cell modeling were presented in terms of reactant (oxygen and hydrogen) concentrations and water concentration in the anode and cathode gases; the polarization curve of the cell was also displayed.
\end{abstract}

Keywords: Maxwell-Stefan equation, molar concentration, polarization curve

\section{Introduction}

A fuel cell has been considered as an efficient and clean alternative power source for automobile industry since the energy crisis forced people to find a substitute for fossil fuels. A proton exchange membrane fuel cell, also known as polymer electrolyte membrane fuel cell (PEMFC), becomes a prime candidate for applications in power systems, submarines, and aerospace applications [1,2], because of its following features: the PEMFC can operate at a relative low temperature (less than $90^{\circ} \mathrm{C}$ ); the PEMFC can start quickly; the PEMFC has a higher current density due to thin membrane electrodes assembly (MEA) compared to other types of fuel cells, and there are no corrosive fluid hazards since there is no liquid electrolyte present in the PEMFC.

The single-cell PEMFC consists of a carbon plate, a gas diffusion layer (GDL), a catalyst layer, for each of the anode and the cathode sides, as well as a PEM membrane at the center. Flow channel geometry is of critical importance for the performance of fuel cells containing proton exchange membranes (PEM) but is of less concern for solid oxide fuel cells (SOFC). The reactants, as well as the products, are transported to and from the cell through flow channels. Flow field configurations, including parallel, serpentine, interdigitated, and other combined versions, have been developed. Nevertheless, the wide application of a PEMFC is limited due to high capital cost, fuel availability and durability. The difficulty of maintaining suitable thermal management and water management also affects the fuel cell performance significantly.

Experimental research and numerical simulation have been used in fuel cell design in order to improve the performance of fuel cells. Experimental data is useful to validate the models. The computational models are efficient in predicting the cell performance under a variety of design parameters. Fuel cell models can be classified into $1 \mathrm{D}, 2 \mathrm{D}$ and $3 \mathrm{D}$ according to dimensions.

Cheddie and Munroe where the first authors who developed a model for high temperature PEMFC [3]. Khazaee and Ghazikhani [4] proposed a complete three-dimensional and single phase model for annular-shaped proton exchange membrane (PEM) fuel cell to investigate the effect of using different connections between bipolar plate and gas 
diffusion layer on the performances, current density, and temperature and gas concentration.

Chiang and Chu [5] investigated the effects of transport components on the transport phenomena and performance of PEM fuel cells by using a threedimensional model. The impacts of channel aspect ratio (AR) and GDL thickness were examined. It was found that a flat channel with a small AR or a thin GDL generates more current at low cell voltage due to the merits of better reactant gas transport and liquid water delivery.

The goal of the present work is to investigate the steady-state transport of reactants and water in a cell including both anode and cathode mass and momentum transport phenomena in the flow channels, gas diffusion layers and porous electrodes. Phosphoric acid $\left(\mathrm{H}_{3} \mathrm{PO}_{4}\right)$ doped polybenzimidazole (PBI) membrane type was used in this simulation, in order to achieve the requested high proton conductivity for the PEM fuel cell.

All application modes are strictly used in their conservative form to account for solid-fluid (gaseous) phase change within the reaction layers as protons may be transported in a solid absorbed state (Grotthuss proton hopping mechanism) through the membrane [6]. Emphasis is put on the material and gas properties for the high operating temperature $\left(180^{\circ} \mathrm{C}\right)$. Operating conditions are carefully declared as boundary conditions at their respective interfaces.

\section{Model set-up}

\subsection{Computational domain}

The 3D computational domain includes a section of the PBI membrane and both cathode and anode gas flow channels, GDLs, and catalyst layers (see Fig.1)

Oxygen $\left(\mathrm{O}_{2}\right)$ or air and hydrogen $\left(\mathrm{H}_{2}\right)$ are supplied via gas channels in counter-flow and diffuse through the gas diffusion layers to the reactive layers where the following oxidation/reduction reactions take place.

On the anode, hydrogen oxidation occurs according to:

$$
H_{2} \Rightarrow 2 H^{+}+2 e^{-}
$$

(no water molecules are assumed to be involved in the proton transport).

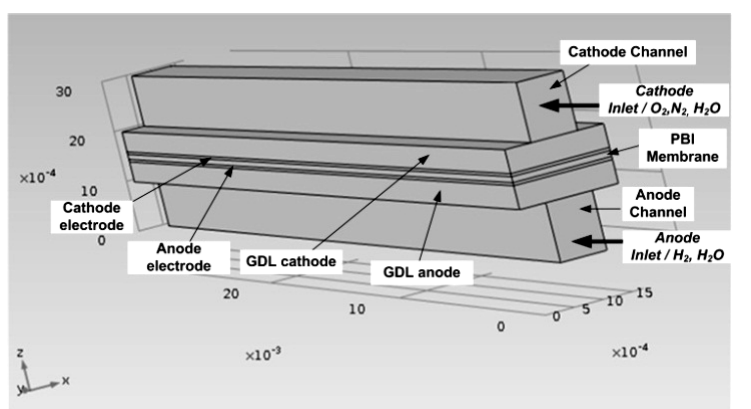

Fig.1. 3D HT-PEMFC computational model geometry.

At the cathode, oxygen reacts together with the protons to form water according to:

$$
\mathrm{O}_{2}+4 \mathrm{H}^{+}+4 e^{-} \Rightarrow 2 \mathrm{H}_{2} \mathrm{O}
$$

The bipolar-plate serves to transport electrical current over the external load where power can be drawn. Protons reach the cathode directly through the membrane. Beside water at the cathode side, heat is produced due to strong exothermic reaction.

The anode GDL boundaries facing the flow pattern ribs are set to zero electronic potential, and the corresponding boundaries at the cathode side are set to the cell potential. All other external boundaries are electrically isolated.

\subsection{Numerical procedure}

COMSOL Multiphysics, a commercial solver based on the finite element technique, is used to solve the following unknown variables: electronic potential $\Phi_{s}$, ionic potential $\Phi_{l}$, hydrogen mass fraction (in the anode compartment) $w_{H 2}$, water mass fraction (in the anode compartment) $w_{\mathrm{H} 2 \mathrm{Oa}}$, oxygen mass fraction (in the cathode compartment) $w_{O 2}$, water mass fraction (in the cathode compartment) $w_{H 2 O c}$, nitrogen mass fraction (in the cathode compartment) $w_{N 2}$, velocity field vector $\mathrm{u}$ and pressure $p$. This is done by coupling two Transport of Concentrated Species interfaces and one Free and Porous Media Flow interface to one Secondary Current Distribution interface. 
The Secondary Current Distribution interface is used for modeling the electrochemical reactions using Ohms law and solving for $\Phi_{s}$ in the GDLs, $\Phi_{s}$ and $\Phi_{l}$ in the porous electrodes, and $\Phi_{l}$ in the electrolyte membrane. In the porous electrodes the local current densities depend on the ionic and electronic potentials, but also on local reactant concentrations. At the flow channel inlet boundaries, laminar inlet flow velocity profiles are specified, whereas a pressure is specified at the flow channel outlet boundaries. To model a multiple parallel channel configuration, symmetry boundary conditions are applied along the long sides of the GDLs and the porous electrodes. All other wall boundaries use no-slip conditions.

To accelerate the convergence, the following procedures are adopted to solve the governing equations: Conductive Media DC module is firstly solved based on the initial setting. Secondly, Darcy's Law and Incompressible Navier-Stokes modules are solved together using the results from the previous calculation as initial conditions. After the previous two modules converge, all the coupled equations including Maxwell-Stefan Diffusion and Convection module are solved simultaneously until the convergence is obtained.

\subsection{Assumptions}

In this model set-up the following assumption are used: i) steady-state operating conditions, ii) as the cell is operated at higher temperatures single-phase water-flow is assumed, iii) since the velocity of the gases is low, laminar flow is assumed, iv) all gases are treated an ideal behavior of gases is considered, v) all electrochemical reactions are gaseous phase reactions and there is no crossover of gases through the membrane, vi) all materials are considered isotropic and homogenous.

\subsection{Governing equations}

\subsubsection{Flow Channels}

Based on the model assumptions, the reactant gas flow in the gas channel is governed by the continuity equation to insure the mass conservation as well as the steady state incompressible NavierStokes equation to describe the momentum conservation of Newtonian fluids. The multi- component diffusion and convection in flow channels are described by the Maxwell-Stefan equation. It solves the fluxes in terms of mass fraction. The general form of the Maxwell-Stefan equation is shown below (1):

$$
\begin{aligned}
& \frac{\partial}{\partial t} \rho \omega_{l}+\nabla \cdot\left[-\rho \omega_{l} \sum_{j=1}^{n} D_{i j}\left\{\frac{M}{M_{j}}\left(\nabla \omega_{j} \frac{\nabla M}{M}\right)+\right.\right. \\
& \left.\left.+\left(x_{j}-\omega_{j}\right) \frac{\nabla P}{P}\right\}+\rho \omega_{l} u\right]=R_{i}
\end{aligned}
$$

where $D_{i j}$ is the diffusion coefficient; x is the molar fraction; $\omega$ is the mass fraction; $M(\mathrm{~kg} / \mathrm{mol})$ is the molecular mass; The subscript $i$ (or $j$ ) represents each species of hydrogen and water on the anode side, and oxygen, water, nitrogen on the cathode side. $R_{i}$ is source term (reaction rate) caused by chemical reactions $\left[\mathrm{kg} \cdot \mathrm{m}^{-3} \cdot \mathrm{s}^{-1}\right]$ and $\rho$ is the gas mixture density.

On the cathode side, the transport equations are solved for two species since the third species can always be obtained from the mass balance equation given as the following (2):

$$
w_{\mathrm{N}_{2}}=1-w_{\mathrm{O}_{2}}-w_{\mathrm{H}_{2} \mathrm{O}} ; w_{\mathrm{H}_{2} \mathrm{O}}=1-w_{\mathrm{H}_{2}}
$$

\subsubsection{Gas diffusion layers and catalyst layers}

Since gas diffusion layers (GDL) and catalyst layers are porous media, the velocity distribution is therefore formulated by Darcy's law and mass conservation equation.

Darcy's law:

$u=-\frac{k}{\mu} \nabla p$

where $\kappa\left(\mathrm{m}^{2}\right)$ is the permeability and $\mu(\mathrm{Pa} \cdot \mathrm{s})$ is the dynamic viscosity.

Continuity equation:

$\nabla \cdot(\rho u)=S$

where $\mathrm{u}(\mathrm{m} / \mathrm{s})$ is velocity vector ; $\mathrm{P}$ is pressure $(\mathrm{Pa})$; $\rho\left(\mathrm{kg} / \mathrm{m}^{3}\right)$ is mixture density; $\mu(\mathrm{kg} / \mathrm{m} \cdot \mathrm{s})$ is dynamic viscosity.

In the catalyst layer, the reaction rate $R_{i}$ corresponding to each species is given as:

$R_{\mathrm{H}_{2}}=-\frac{j_{a}}{2 F} M_{\mathrm{H}_{2}} ; R_{\mathrm{O}_{2}}=-\frac{\left|j_{c}\right|}{4 F} M_{\mathrm{O}_{2}} ; R_{\mathrm{H}_{2} \mathrm{O}}=-\frac{\left|j_{c}\right|}{4 F} M_{\mathrm{H}_{2} \mathrm{O}}$ 
where $F$ is Faraday constant $\left[\mathrm{C} \cdot \mathrm{mol}^{-1}\right]$ and $j_{\mathrm{a}}, j_{\mathrm{c}}$ are the transfer current density corresponding to the electrochemical reaction at the anode and cathode catalyst layers, respectively, which were calculated by using a simplified Butler-Volmer equation; the expressions for $j_{\mathrm{a}}$ and $j_{\mathrm{c}}$ were described in details in[7].

\subsubsection{Conservation of electric charge}

In a PEMFC, the current can be split into two parts: ionic current and electronic current. Protons travel through the ionic conductor (membrane) to form an ionic current, while electrons transfer only through the solid matrix of electrodes, which results in an electronic current. The current continuity equations are obtained by using Ohm's law:

$$
\begin{aligned}
& \nabla \cdot\left(-\sigma_{s} \nabla \cdot \phi_{s}\right)=S_{S} \\
& \nabla \cdot\left(-\sigma_{m} \nabla \cdot \phi_{m}\right)=S_{m}
\end{aligned}
$$

where $\Phi$ is the phase potential, $\sigma$ is the effective electric conductivity $\left(\mathrm{S} \mathrm{m}^{-1}\right), S$ is the current source term $\left(\mathrm{A} \mathrm{m}^{-3}\right)$, and the subscript $s$ denotes the property of the solid phase while $\mathrm{m}$ denotes that of the membrane. The source terms in the electron and proton transport equations result from the electrochemical reaction, which occurs only in the catalyst layers of anode and cathode sides, and are given as:

- anode catalyst layer: $S_{m}=j_{a} ; S_{s}=-j_{a}$

- cathode catalyst layer: $S_{m}=j_{c} ; S_{s}=-j_{c}$

\subsection{Boundary Conditions}

The boundary conditions for the model in this study are as follows: i) continuity at all internal boundaries, ii) no slip boundary condition for all channel walls, iii) all initial values set to zero, iv) velocity and temperature defined at channel inlet, step function used for these two parameters in time dependent study, v) no backpressure at channel outlet, convective flux boundary conditions applied, vi) constrain outer edges set to zero for both inlet and outlet, vii) bipolar plates on the most side of the cell set to electric ground and cell operation potential, viii) HTPEM fuel cell is insulated from the environment .

\section{Results and Discussions}

All the base parameters used in the PEM cell modeling are presented in Table 1.

\begin{tabular}{|c|c|}
\hline Description & Value \\
\hline Cell length & $2 \mathrm{~cm}$ \\
\hline Channel height & $1 \mathrm{~mm}$ \\
\hline Channel width & $0.78 \mathrm{~mm}$ \\
\hline Rib width & $0.9 \mathrm{~mm}$ \\
\hline GDL width & $0.38 \mathrm{~mm}$ \\
\hline Porous electrode thickness & $50 \mu \mathrm{m}$ \\
\hline Membrane thickness & $100 \mu \mathrm{m}$ \\
\hline GDL porosity & 0.4 \\
\hline GDL permeability & $1.18 \cdot 10^{-11} \mathrm{~m}^{2}[8]$ \\
\hline GDL electric conductivity & $222 \mathrm{~S} / \mathrm{m}[9]$ \\
\hline GDL ionic conductivity & $9.825 \mathrm{~S} / \mathrm{m}[10]$ \\
\hline Inlet $\mathrm{H}_{2}$ mass fraction (anode) & 0.743 \\
\hline $\begin{array}{l}\text { Inlet } \mathrm{H}_{2} \mathrm{O} \text { mass fraction } \\
\text { (cathode) }\end{array}$ & 0.023 \\
\hline $\begin{array}{l}\text { Inlet oxygen mass fraction } \\
\text { (cathode) }\end{array}$ & 0.234 \\
\hline Anode inlet flow velocity & $0.2 \mathrm{~m} / \mathrm{s}$ \\
\hline Cathode inlet flow velocity & $0.5 \mathrm{~m} / \mathrm{s}$ \\
\hline Anode viscocity & $1.19 \cdot 10^{-5} \mathrm{~Pa} \cdot \mathrm{s}$ \\
\hline Cathode viscosity & $2.46 \cdot 10^{-5} \mathrm{~Pa} \cdot \mathrm{s}$ \\
\hline Hydrogen molar mass & $0.002 \mathrm{Kg} / \mathrm{mol}$ \\
\hline Nitrogen molar mass & $0.0028 \mathrm{Kg} / \mathrm{mol}$ \\
\hline Water molar mass & $0.018 \mathrm{Kg} / \mathrm{mol}$ \\
\hline Oxygen molar mass & $0.032 \mathrm{Kg} / \mathrm{mol}$ \\
\hline $\begin{array}{c}\mathrm{H}_{2}-\mathrm{H}_{2} \mathrm{O} \text { Binary diffusion } \\
\text { coefficient }\end{array}$ & $180.76 \cdot 10^{-6} \mathrm{~m}^{2} / \mathrm{s}$ \\
\hline $\begin{array}{c}\mathrm{N}_{2}-\mathrm{H}_{2} \mathrm{O} \text { Binary diffusion } \\
\text { coefficient }\end{array}$ & $5.0559 \cdot 10^{-5} \mathrm{~m}^{2} / \mathrm{s}$ \\
\hline $\begin{array}{l}\mathrm{O}_{2}-\mathrm{N}_{2} \text { binary diffusion } \\
\text { coefficient }\end{array}$ & $4.7131 \cdot 10^{-5} \mathrm{~m}^{2} / \mathrm{s}$ \\
\hline $\begin{array}{c}\mathrm{O}_{2}-\mathrm{H}_{2} \mathrm{O} \text { binary diffusion } \\
\text { coefficient }\end{array}$ & $5.5394 \cdot 10^{-5} \mathrm{~m}^{2} / \mathrm{s}$ \\
\hline Cell temperature & $453.15 \mathrm{~K}$ \\
\hline Reference pressure & $101000 \mathrm{~Pa}$ \\
\hline Cell voltage & $0.9 \mathrm{~V}$ \\
\hline Permeability (electrode) & $2.36 \cdot 10^{-12} \mathrm{~m}^{2}$ \\
\hline $\begin{array}{c}\text { Anode exchange current } \\
\text { density }\end{array}$ & $1 \cdot 10^{5} \mathrm{~A} \cdot \mathrm{m}^{-2}[11]$ \\
\hline $\begin{array}{l}\text { Cathode exchange current } \\
\text { density }\end{array}$ & $1 \mathrm{~A} \cdot \mathrm{m}^{-2}[11]$ \\
\hline
\end{tabular}

Table 1 Base model Parameters 
Figure 2 presents the polarization curve obtained from numerical simulation of the cell model. The simulations of the actual model were made based on the gas channel dimensions, membrane properties, operating conditions, stoichiometric ratio and the current density obtained from the experimental testing of a PEMFC cell [7].

The current density predicted by this numerical model was very close to the experimental current density used to calculate the corresponding input velocity.

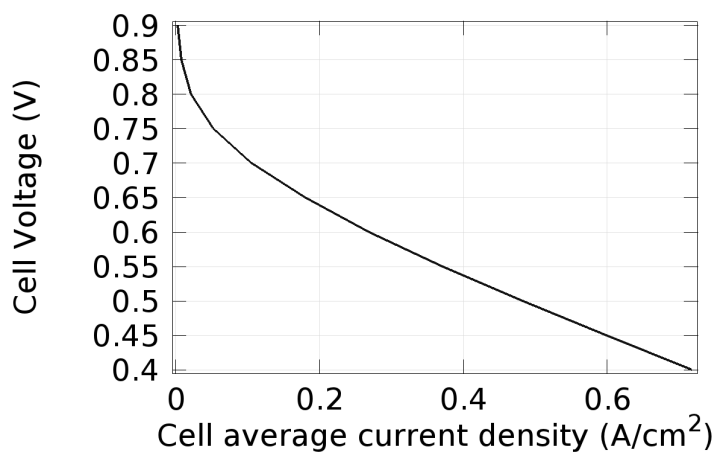

Fig.2. Polarization plot for PEMFC cell model.

Figures 3 and 4 show the reactants (hydrogen and oxygen) concentration in the cathode and anode gases at $0.4 \mathrm{~V}$.

In fig. 3 it can be observed that the hydrogen concentration level is quite uniform; it is interesting to note that the hydrogen concentration slightly decreases as the anode gas flows from the inlet (at the bottom) to the outlet (at the top). This means that the resulting convective flux of anode gas towards the membrane causes the concentration of hydrogen to go down with a small amount.

The oxygen concentration at cathode (see fig.4) decreases along the flow direction( from right to left in the figure) and across the membrane direction due to the consumption of fuel in the electrochemical reaction at the catalyst layer, since the consumption rate is proportional to the cell operating current density. A lower fuel concentration gradient is found at $0.8 \operatorname{volt}\left(1.0038 \mathrm{~mol} / \mathrm{m}^{3}\right.$ - the maximum molar concentration), which is due to the slower consumption of fuel when the cell is working at high output voltage but low current density.

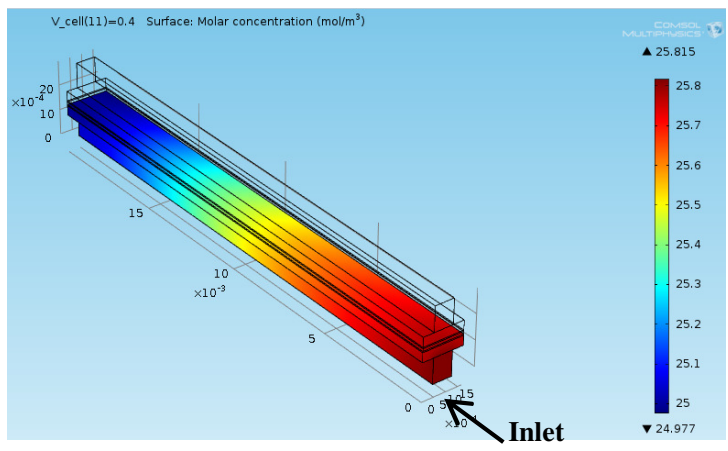

Fig.3. Hydrogen concentration at anode, at $0.4 \mathrm{~V}$.

A small change in the oxygen flow gives a substantial change in cell polarization.

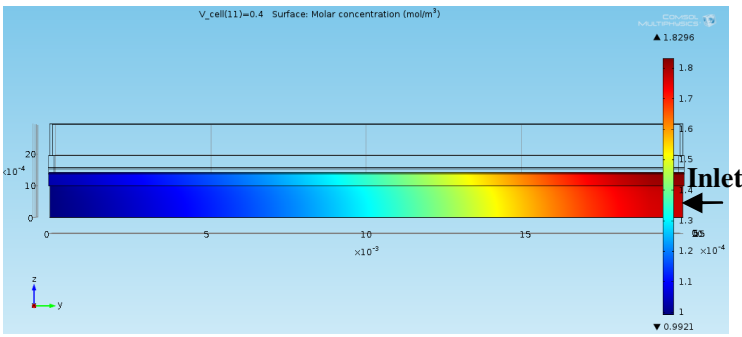

Fig.4. Oxygen concentration at the cathode in the cell at $0.4 \mathrm{~V}$, in $\mathrm{Z}-\mathrm{Y}$ mode.

Figures 5 and $\mathbf{6}$ depict the water concentration in the anode and cathode gases. It is clear that water is transported through diffusion and convection to the membrane on the anode side.

The concentration increase due to water production at the cathode is much larger than the effect of removing hydrogen from the gas stream at the anode for these flow and current levels.

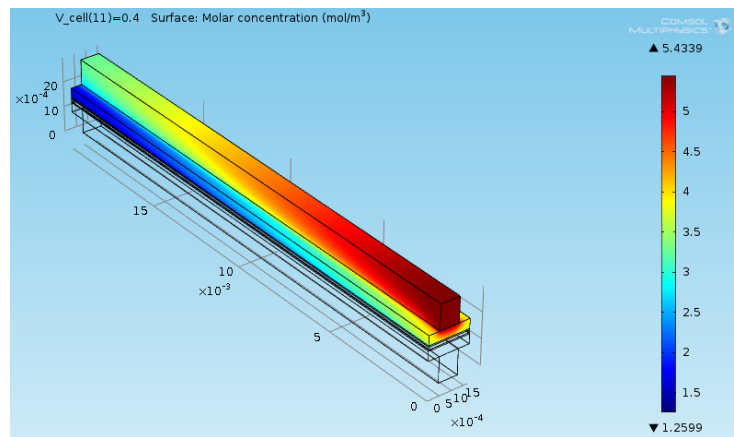

Fig.5. Anode water concentration at $0.4 \mathrm{~V}$. 


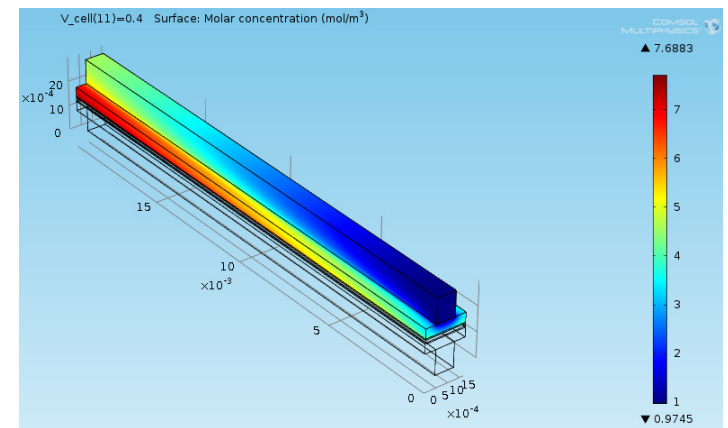

Fig.6. Cathode water concentration at $0.4 \mathrm{~V}$.

The results showed that a minimum occured at the upper corner of the membrane on the anode side that limits fuel cell performance(see fig.5). If the anode gas becomes too dry, the membrane dries out, resulting in a decrease in ionic conductivity and failure of fuel cell. On the other hand, at the cathode side the water levels increased with the direction of flow and a local maximum in water current appeared at the upper corner of the membrane (see fig.6). If the local maximum in water current would be located in the lower corner, the situation would be critical since the water droplets could clog the pores and effectively hinder gas transport to the active layer.

\section{Conclusions}

Three-dimensional, single-phase and isothermal model of HT- PEM fuel cell have been developed at one operation voltage. The model is able to investigate the transport phenomena and electrical potential distribution for the various PEM fuel cell components including the gas channels, gas diffusion layers, catalyst layers and membrane.
From the cathode side of the cell, the water concentration presented a local maximum in upper corner of the membrane, allowing gas transport to the active layer. The computed polarization curve of the 3D model for proton exchange membrane fuel cell was achieved good agreement with experimental polarization curve.

\section{References}

* E-mail address : ionescu.vio@gmail.com

[1]. J. Larminie, and A. Dicks, Fuel cell system explained, John Wiley and Sons., $2^{\text {nd }}$ edition, 2003.

[2]. F. Laurencelle, R. Chahine, J. Hamelin , K. Agbossou, M. Fournier, T.K. Bose et al. Fuel Cells J 1, 166 (2001).

[3]. D. Cheddie and N. Munroe, J. Power Sources 156, 414 (2006).

[4]. I. Khazaee, and M. Ghazikhani, Journal of Power Sources 196, 2661 (2011).

[5]. M.S. Chiang, and H.S. Chu, Journal of Power Sources 160, 340 (2006).

[6]. R. Bouchet, and E. Siebert, Solid State Ionics, 118, 287 (1999)

[7]. E. U. Ubong, Z. Shi, and X. Wang, Journal of The Electrochemical Society 156(10) 1276(2009).

[8]. D.F. Cheddie and N.D.H. Munroe, J. Power Sources, 160, 215 (2006).

[9]. http://www.etekinc.com/standard/index.php, 2008.

[10]. H. L. Lin, T. L. Yu, W. K. Chang, C. P. Cheng, C. R. Hu, and G. B. Jung, J. Power Sources, 164, 481(2007).

[11]. K. Broka, Techn. Lic. Thesis, Royal Institute of Technology, Stockholm, 1995. 